\title{
Covid-19: exploring the "new normal" in gastroenterology training
}

\author{
K. Ekmektzoglou ${ }^{1,2^{*}}$, G. Tziatzios ${ }^{3 *}$, K. Siau ${ }^{4}$, K.M. Pawlak ${ }^{5}$, T. Rokkas ${ }^{1,2}$, K. Triantafyllou ${ }^{3}$, M. Arvanitakis ${ }^{6}$, P. Gkolfakis ${ }^{6,7}$
}

(1) School of Medicine, European University Cyprus, Nicosia, Cyprus; (2) Gastroenterology Clinic, Henry Dunant Hospital, Athens, Greece; (3)Hepatogastroenterology Unit, Second Department of Internal Medicine, Propaedeutic, Medical School, National and Kapodistrian University of Athens, "Attikon" University General Hospital, Athens, Greece; (4) Department of Gastroenterology, The Dudley Group NHS Foundation Trust, Dudley, UK; (5) Department of Internal Medicine, Cardiology, Gastroenterology and Endocrinology, Hospital of the Ministry of Interior and Administration, Szczecin, Poland; (6) Department of Gastroenterology, Hepatopancreatology and Digestive Oncology, Erasme University Hospital, Université Libre de Bruxelles, Brussels, Belgium; (7) Department of Medical Oncology, Institut Jules Bordet, Brussels, Belgium.

\begin{abstract}
The coronavirus disease 2019 (COVID-19) pandemic has led to unprecedented disruptions in fellowship training programs worldwide. In gastroenterology, the strain in healthcare service provision and the emphasis on preventing viral transmission has adversely impacted hands-on training opportunities, with trainees facing the constant pressure to meet training requirements under the continuous threat of viral transmission. Emerging evidence highlight the scale of the problem, specifically with regard to endoscopy competence due to cancellation of elective endoscopic procedures, provision of inpatient and outpatient consultative care as well as academic education and the mental well-being of trainees. As such, it has been necessary for trainees, trainers and training programs collectively to adapt to these challenges and incorporate novel and adaptive solutions to circumvent these training barriers. This review aims to summarise data on the globa impact of COVID-19 on gastroenterology training and the practical interventions that could be implemented. (Acta gastroenterol. belg., 2021, 84, 627-635).
\end{abstract}

Keywords: COVID-19, education, gastroenterology, endoscopy, training, interventions.

\section{Introduction}

The Coronavirus Disease 2019 (COVID-19) pandemic has had far reaching disruptions on almost all walks of medicine, including gastroenterology healthrelated services and training. In Europe, preliminary data are alarming; studies report a more than $90 \%$ reduction in all endoscopic procedures performed by trainees. Causes include redeployment towards non-endoscopy departments (COVID-19 departments), reduction of hands-on training, changes to institutional policies, and mentorship unavailability (1). The classic apprenticeship model for acquiring endoscopic skills of "learning by doing" or even fulfilling competency-based curricula has been put on strain by the COVID-19 measures, which has led to compromises in trainee education and autonomy (2). The American Gastroenterological Association (AGA), European Society of Gastrointestinal Endoscopy (ESGE) and European Society of Gastroenterology Nurses and Associates, in their recently published Guidelines regarding best practice in endoscopic procedures during the COVID-19 pandemic, opted for a profound reorganization of the gastroenterology departments advocating in favor of only essential and fully trained personnel being present in endoscopy suites $(3,4)$. This causes increasing challenges since the unsatisfactory quality of endoscopy training was pre- viously observed in trainees' curriculum, in the preCOVID-19 era. According to the 2016 British Society of Gastroenterology (BSG) trainees' survey of endoscopy training, $12.5 \%$ of trainees had no access to a regular training list, with $53 \%$ of final year trainees not achieving full certification in colonoscopy. A significant percentage $(9 \%)$ of final year trainees reported not feeling confident in upper gastrointestinal (GI) bleeding endoscopic management (5).

During the COVID-19 pandemic GI departments downsized inpatient consultation services, embraced virtual forums for educational activities and minimized fellows participating in endoscopic procedures (6-10), while scientific societies published guidance for trainees (11). In this article, we aimed to review the impact of the COVID-19 outbreak in gastroenterology training with regard to trainee training and their well-being. To retrieve relative literature, we conducted a PUBMED search for all articles published in English language till $30^{\text {th }}$ November 2020 including the terms "COVID-19" and "gastroenterology or endoscopy training".

\section{COVID-19 impact on gastroenterology training}

Data from international and national surveys

Pawlak et al. (12), undertook an international survey regarding the COVID-19 outbreak recruiting 770 gastroenterology trainees from 63 countries. The primary outcome was the reduction in monthly procedure volume before and during COVID-19. The vast majority of participants $(93.8 \%)$ reported a significant $(p<0.0001)$ reduction in endoscopic procedures of all types. Moreover, the median percentage reduction in procedural volume was 99\% [interquartile range (IQR), $85 \%-100 \%]$, a finding that varied by procedure type $(p<0.001)$, but not by trainee specialty $(p=0.658)$ or whether procedures were performed under supervision or independently $(\mathrm{p}=0.614)$. Colonoscopy was the endoscopic procedure with the higher percentage reductions

Correspondence to: Paraskevas Gkolfakis MD, Department of Gastroenterology, Hepatopancreatology and Digestive Oncology, Erasme University Hospital, Université Libre de Bruxelles, Brussels, Belgium.

* These authors contributed equally to this work.

E-mail: paraskevas.gkolfakis@erasme.ulb.ac.be

Submission date : 19/04/2021

Acceptance date : 25/05/2021 
(median, 100\%; IQR, 88\%-100\%) vs. endoscopic retrograde cholangiopancreatography (ERCP) (median, $100 \%$; IQR, 60\%-100\%; $\mathrm{p}=0.003$ ) and upper GI bleeding procedures (median, 100\%; IQR, 50\%-100\%; $<<0.001$ ]. Of interest, $73.5 \%$ and $3.6 \%$ of the trainees reported a $\geq 50 \%$ decrease or cancellation of all endoscopic activities, respectively. The most important reductions were seen in Europe and North America compared to Asia and South America $(\mathrm{p}<0.001)$. Among trainees who still had access to endoscopic procedures, 36.1\% could perform endoscopy on patients at low risk or negative for COVID-19, whereas only $6.2 \%$ reported no endoscopic restrictions. Key barriers to endoscopic training included institutional policy changes (79.9\%), a reduced number of patients $(58.3 \%)$ and limited availability of personal protection equipment (PPE) $(28.8 \%)$. These results were confirmed in a national level when the aforementioned survey was distributed among UK trainees (132 responders) (13). Among different endoscopic procedures, the most significant difference was noted between upper GI bleeding procedures (mean reduction 78\%) and ileocolonoscopy (mean reduction $97.2 \% ; p<0.0001)$. Once again, these differences reported were attributed to institutional policies that excluded trainees from procedures $(75.8 \%)$, lack of cases $(56.8 \%)$, and reassignment to other clinical areas $(47.7 \%)$. All participants reported a reduction in the endoscopy case volume with $96.0 \%$ of them reporting a $>50 \%$ reductions.

In the study conducted by the Italian Association of Young Gastroenterologist and Endoscopist (AGGEI) 183 trainees in gastroenterology and/or young gastroenterologists were included (14). Almost all participants (96.7\%) reported a change of daily activity in their units during the COVID-19 outbreak with a $91 \%$ reduction of the endoscopic volume compared to the activity before the COVID-19 outbreak. Interestingly enough, $84.5 \%$ of the participants felt that the COVID-19 outbreak had an impact on the training curriculum due to mentorship unavailability and procedural trainees' involvement interruption (52.6\% and $66.4 \%$, respectively). Across the Atlantic, Clarke et al. (15), reported the results of a survey among 177 gastroenterology fellows. More than half $(53.9 \%)$ reported partial restriction in endoscopic procedures (fellows could participate while on call, but not for routine cases), with $18.5 \%$ reporting complete restriction. The only study published so far researching the COVID-19 impact on pediatric gastroenterology fellow training (United States, Canada and Mexico) revealed similar findings (16). Overall, in 43\% and 52\% of the training programs fellows stopped participating in outpatient clinics and endoscopy, respectively. Similarly, $51 \%$ of the programs directors reported reduced numbers of on-site fellow inpatients consultations, with $27 \%$ reporting rates of $\geq 50 \%$.

\section{Single-center experience}

A retrospective study from two European large-capacity endoscopy units (17) compared 2 different timeframes [before (2019) and during the COVID-19 era (2020)]. Trainees' involvement in esophagogastroduodenoscopies (EGD) and ileocolonoscopies significantly reduced between the two periods [from 245/709 (34.6\%) to $101 / 370(27.3 \%)$ and from $208 / 426(48.8 \%)$ to $28 / 162$ (17.3\%), respectively; $\mathrm{p} \leq 0.015]$. Similar reduction was noted for ERCP [from 63/87 (72.4\%) to 35/73 (47.9\%); $\mathrm{p}<0.001]$. Overall, the most significant decrease in trainees' involvement was noted in ileocolonoscopy [Prevalence Odd's ratio (POR) (95\% CI): 0.219 (0.139$0.343)]$. These data are in line with results from a tertiary care hospital in Germany, where gastroenterology fellows had to be transferred to ICUs and infectious disease units leading to a $56 \%$ reduction of fellows' participation in endoscopic procedures in just 4 months (January 2020-April 2020) (18). In an Italian center 12 doctors had started training in the first trimester of 2020, but immediately after Italy was declared in a state of emergency all of them left (19). Even more alarming was the fact that the general administration of the hospital ceased all types of scientific studies, patient screenings, follow-up, and protocol(s) enrollment (20). In a single center study conducted at an academic medical center in Pennsylvania the authors demonstrated a significant disruption of first-year endoscopic training and estimated that the current first year fellows would experience a significant delay in their competence assessment according to the ASGE core curriculum since they would not be able to perform almost $20 \%$ of the procedures needed to reach that level (21). Palchaudhuri et al. (22), briefly described changes imposed by the COVID-19 outbreak in their Pennsylvania gastroenterology 6 fellows/year fellowship program. With 30 residents being quarantined at the beginning of the epidemic, rounds were conducted on a virtual platform and no trainee was allowed in the endoscopy suite due to the high risk of exposure and, of note, due to limited PPE access. Research laboratories were closed and outpatient procedures were substantially reduced. To substitute for the aforementioned changes a revised program aiming to minimize overlapping of team members and cumulative exposure per fellow was introduced. A fellow was assigned to an attending at each site rotating between them tandem and each fellow was on service for only a week at a time with a week break. Finally, all pre-existing didactic activities were converted into virtual sessions. Similar experience was reported by Ong et al. (23) in Singapore, where many gastroenterology residents stopped their training and were allocated to work in isolation and pneumonia wards. At that case endoscopy theoretical training was substituted, exclusively, by online material. Studies exploring the impact of COVID-19 on endoscopy training are summarized in Fig 1.

\section{COVID-19 impact on trainee well-being}

Burnout, a psychological syndrome characterized by exhaustion, cynicism, and inefficiency is a chronic 

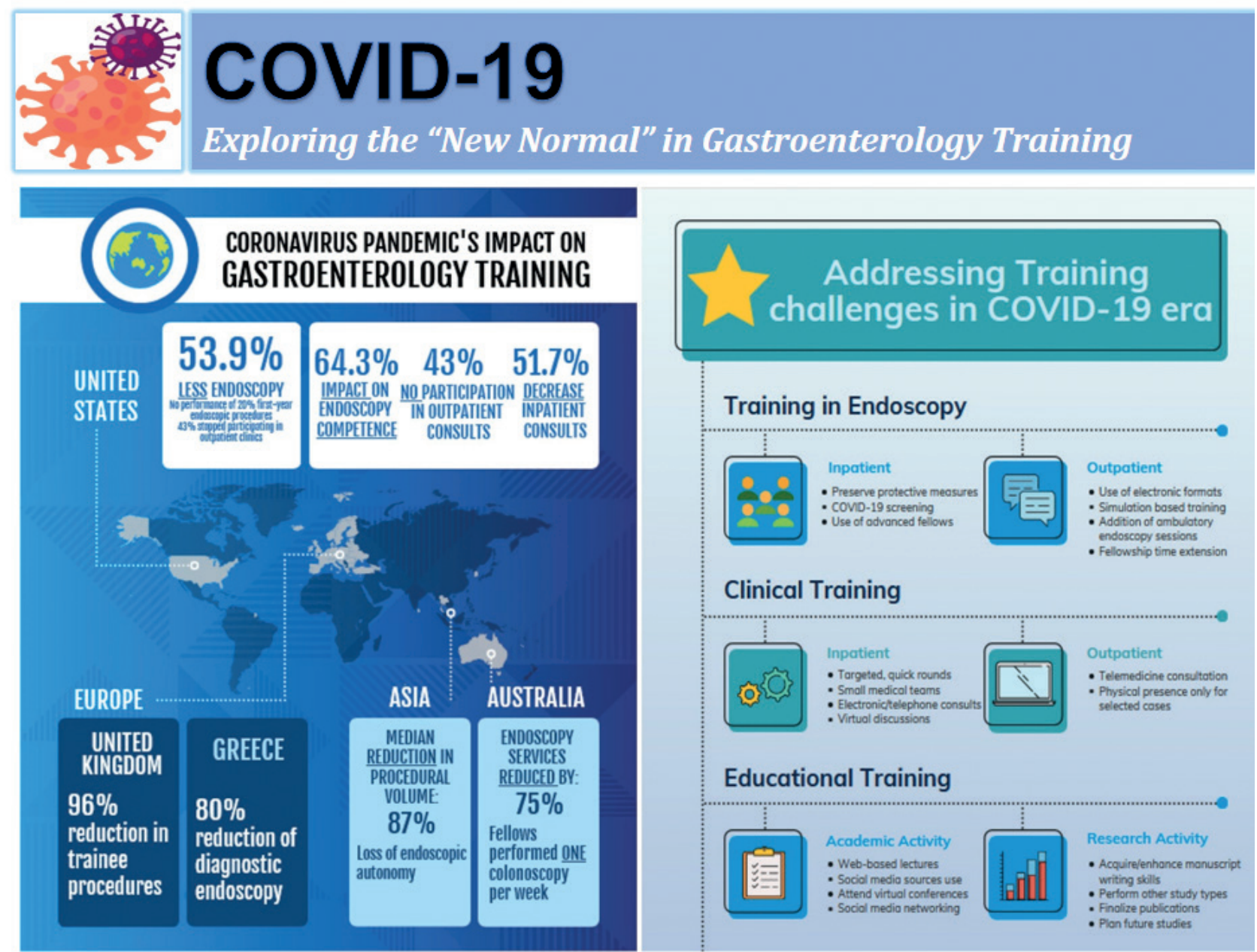

Figure 1. - Infographic summarizing the impact of COVID-19 on gastroenterology training and how to address it.

progressive medical entity that can ultimately lead to real life morbidity and even mortality. A plethora of risk factors that can possibly lead to a burnout, among them younger physician's age (trainees/residents), procedure complexity, procedure-related adverse events, work-life imbalance, and changes in health care reimbursement, have been destabilized in the COVID-19 era. Three major components of burnout searched in clinical studies include emotional exhaustion, depersonalization, and low sense of personal accomplishment $(24,25)$. A worldwide anonymous, voluntary, web-based survey that was undertaken in midst of the COVID-19 pandemic among 319 fellows (85 GI trainees) revealed that trainees taking care of COVID-19 patients were increasingly more likely to report burnout compared with trainees who did not take care of patients with COVID-19 (26). In the international survey by Pawlak et al. (12), trainees expressed their concerns about the impact of COVID-19 on their physical health. In details, $79.3 \%$ were concerned with being infected with the virus, while $23.9 \%$ reported taking time off work for COVID-19related reasons, $76.8 \%$ for themselves and the remaining $23.4 \%$ for a member of their family. Of interest, more than half of the trainees (52.4\%) reported mild, moderate or severe anxiety, that was independently associated with female gender, PPE adequacy, lack of institutional support for emotional health, and training prolongation concerns [odds ratio $[\mathrm{OR}] \geq 1.60 ; \mathrm{p} \leq 0.013$ ]. Finally, up to $18.8 \%$ of trainees met the criteria for burnout, Similarly, in the UK study half of the trainees reporting experiencing significant anxiety, while $10.8 \%$ officially met the criteria for burnout. What is comforting though was that institutional emotional support strategies were available to $90.8 \%$ of trainees (13). On the other hand, in the study conducted in Singapore, staff personal interactions with residents revealed several factors that potentially contributed to worsening burnout (23). Gastroenterology residents assigned to COVID-19 wards lost all physical contact with their colleagues due not only to isolated working environmental surroundings but, also, due to many imposed self-isolation periods away from their families, thereby, virtually, levelling all social interactions. Needless to say, working beyond their specialty-related competencies, handling high-qualified non-endoscopic instruments and caring for large numbers of infectious patients with a poorly understood disease may cross the trainees' comfort zone alongside their well-being. Some of the interventions implemented to cope with increasing fear and burnout issues included a 24-hour psychologist hotline, provision of formal letters 


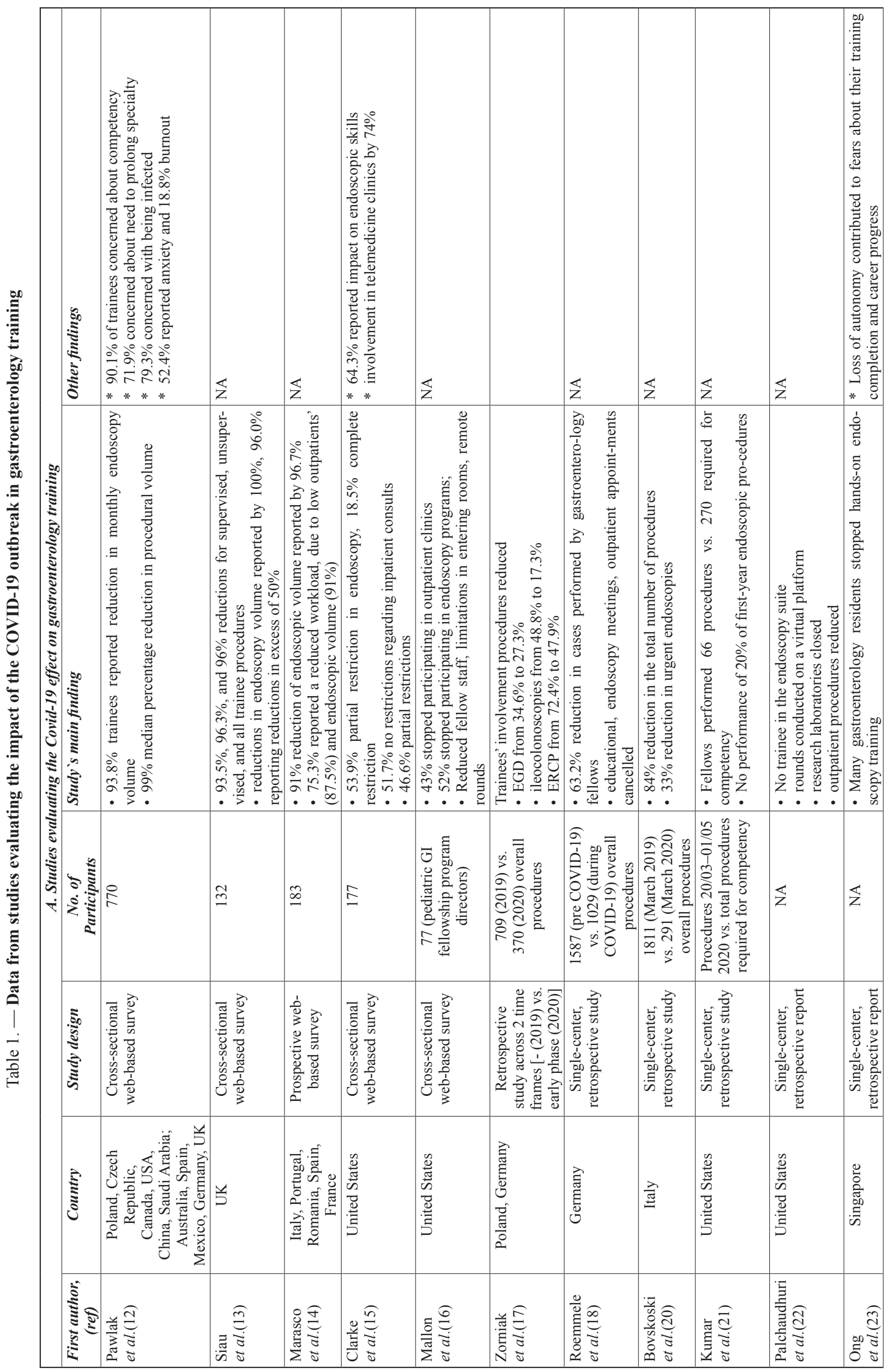




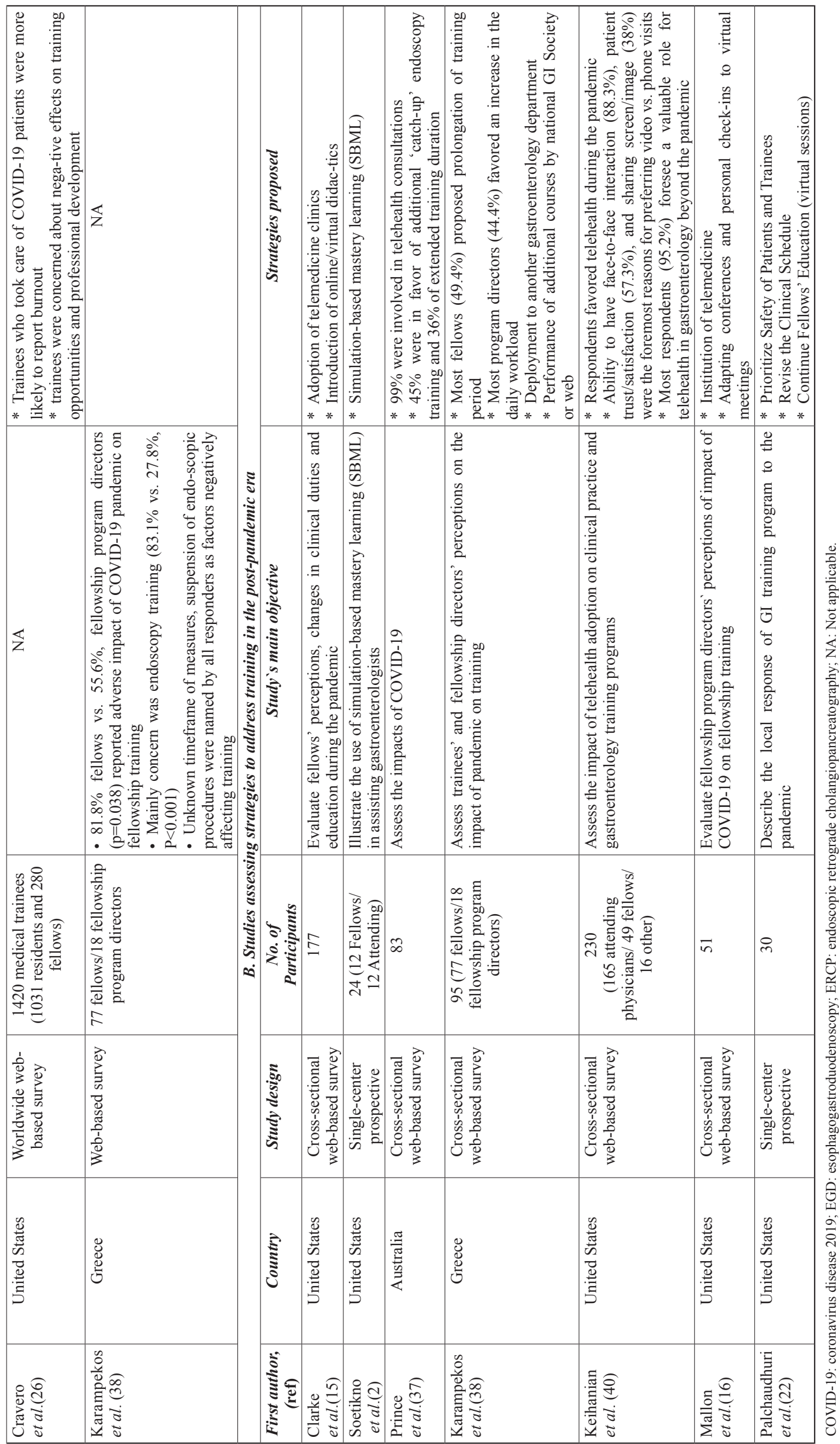


Table 2. - Challenges during GI fellowship training and potential measures to address them in the COVID-19 era

\begin{tabular}{|c|c|c|c|}
\hline \multirow{3}{*}{$\begin{array}{l}\text { Training in } \\
\text { Endoscopy }\end{array}$} & Setting & Problems & Potential Solutions \\
\hline & Outpatient & $\begin{array}{l}\text { - Reduction of endoscopy volume due to postponement } \\
\text { of scheduled elective endoscopic procedures (screening } \\
\text { colonoscopy) affects acquiring/maintaining competence in } \\
\text { endoscopic skills } \\
\text { - Reduction of endoscopy volume affects technical and } \\
\text { cognitive domain of endoscopy competence } \\
\text { - Limited participation by fellows does not allow sufficient } \\
\text { procedural volume to be achieved } \\
\text { - Unknown timeframe of measures implementation in } \\
\text { hospitals }\end{array}$ & $\begin{array}{l}\text { (1) Teaching on endoscopic procedures using electro- } \\
\text { nic formats (e.g. endoscopy videos or virtual reality } \\
\text { sessions) - Tele-endoscopy } \\
\text { (D) Adopt simulation-based training methods (simula- } \\
\text { tor models) and Hands-on Models } \\
\text { (D) GI societies conduct virtual and live-streaming } \\
\text { endoscopy events } \\
\text { (D) Add ambulatory endoscopy sessions (e.g., evening } \\
\text { and/or weekend sessions) } \\
\text { (D) Extension of fellowship program time } \\
\text { (D) Deployment to another gastroenterology department }\end{array}$ \\
\hline & Inpatient & $\begin{array}{l}\text { - Limited involvement of fellows during procedures due to } \\
\text { exposure to COVID-19 } \\
\text { - Lack of personal protective equipment } \\
\text { - Limited involvement of fellows affects competence in } \\
\text { performance of emergency endoscopic procedures }\end{array}$ & $\begin{array}{l}\text { (5) Preserve protective measures } \\
\text { (5) Appropriate COVID-19 screening and clearance } \\
\text { prior to procedure } \\
\text { (4) Incorporation of the advanced fellow back in the } \\
\text { endoscopy room }\end{array}$ \\
\hline \multirow[b]{2}{*}{$\begin{array}{l}\text { Clinical } \\
\text { Training }\end{array}$} & Outpatient & $\begin{array}{l}\text { - Cancelled outpatient activities i.e. consultations } \\
\text { - Potential impact on training in treating patients in gastro- } \\
\text { enterology-specific fields (i.e. inflammatory bowel diseases, } \\
\text { hepatology) }\end{array}$ & $\begin{array}{l}\text { (1) Implement telemedicine consultative training } \\
\text { (4) Consults with physical presence only for selected } \\
\text { cases and with use of protective equipment }\end{array}$ \\
\hline & Inpatient & $\begin{array}{l}\text { - Cancelled team-based rounds due to social distancing } \\
\text { - Lack of personal protective equipment } \\
\text { - Need for minimal patient contact and exposure }\end{array}$ & $\begin{array}{l}\text { (5) Targeted and quick patient rounds } \\
\text { (5) Small tactical medical teams } \\
\text { (5) Electronic or telephone consults or only chart } \\
\text { review/discussion } \\
\text { (5) Virtual discussion with other team members or } \\
\text { multidisciplinary team for complex cases }\end{array}$ \\
\hline \multirow[t]{2}{*}{$\begin{array}{l}\text { Educational } \\
\text { Training }\end{array}$} & $\begin{array}{l}\text { Academic } \\
\text { activity }\end{array}$ & $\begin{array}{l}\text { - Cancellation of traditional didactic sessions within each } \\
\text { department } \\
\text { - Cancellation of regional, national and international con- } \\
\text { gresses } \\
\text { - Limited networking and communication opportunities }\end{array}$ & $\begin{array}{l}\text { (5) Local web-based lectures focusing on interactive } \\
\text { learning (grand rounds, journal clubs, fellow } \\
\text { lectures, clinical cases presentation) } \\
\text { (5) Make the most out of social media sources i.e. video } \\
\text { streaming and e-learning platforms, webinars or } \\
\text { lectures via GI societies } \\
\text { (5) Virtual conferences at all levels national or } \\
\text { international } \\
\text { (D) Social media networking guided from GI societies }\end{array}$ \\
\hline & $\begin{array}{l}\text { Research } \\
\text { activity }\end{array}$ & $\begin{array}{l}\text { - Suspension of clinical and laboratory research programs } \\
\text { that involve patient enrollment } \\
\text { - Limited research time due to increased clinical activities }\end{array}$ & $\begin{array}{l}\text { (1) Acquire or enhance manuscript writing skills } \\
\text { (4) Consider performing studies that do not require } \\
\text { actual patient enrollment (retrospective chart } \\
\text { reviews, survey studies, reviews, meta-analysis) } \\
\text { (D) Finalize publication of completed researches } \\
\text { (1) Plan future studies i.e. COVID-related }\end{array}$ \\
\hline
\end{tabular}

from the program to recognize residents' rotations in COVID-19 wards as part of their training, the creation of supplementary teaching programs for those whose training was disrupted or, even, a 'no questions asked' policy in the event of any resident taking a sick leave $(23,27)$. Table 1 summarizes the characteristics of studies assessing the impact of COVID-19 on gastroenterology training and trainee's well-being.

\section{Addressing fellowship training challenges in COVID-19 era}

\section{Training in Endoscopy}

Now that the disruptions caused by the COVID-19 pandemic on endoscopy training worldwide has been quantified (21), urgent action is needed to prioritize skills development in endoscopy. Several solutions could be implemented to maintain cognitive and manual skills development (Table 2). First, teaching on endoscopic procedures could be shifted towards implementation of electronic media formats (e.g. endoscopy video rounds or virtual reality sessions) (22). High-quality, full-length video sessions reviewing common but also advanced and novel technical aspects of endoscopy can be assessed nowadays not only in social media and YouTube but also through sophisticated e-learning platforms, supported by the major GI societies. Similarly, webinars organized at a regular basis by ESGE and other societies host renounced clinicians offering the attendees the opportunity to "meet the expert" and gain from their experience, through simultaneous, interactive discussion. Optimizing existing resources could be also achieved through teleendoscopy, as an evolution from telemedicine (28). This refers to real-time exhibition of procedures performed in the endoscopy suite (i.e. hemostasis for GI bleeding, resection of colorectal lesions, etc.) during which fellows can observe, pose questions and later on discuss with attending physicians about the various aspects of the procedure. These solutions have clearly considerable advantages, namely its widespread availability and accessibility, low-cost and easy-to-use, with its benefit being more profound in terms of the cognitive domain of endoscopy competence (application of endoscopically derived information to clinical practice i.e. knowledge of procedural indications and contraindications, pathology identification). On the other hand, its impact on the technical domain (i.e. torque steering, loop-reduction techniques) of endoscopy competence remains elusive, 
while one might question their scientific validity given the fact that posted content does not undergo a rigorous peer review process. Real world data however can be rather different; results from a survey showed that only $29.1 \%$ of the participants used at least weekly social media-based education alongside endoscopy journals $(15.8 \%)$, online courses from gastroenterology societies $(15.0 \%)$, and institutional distant learning (9.2\%). The most worrisome data however, reflect a significant percentage of trainees $(37.5 \%)$ that did not access any alternate educational resources for endoscopy training (13). Another interesting initiative, to compensate for the clinical and endoscopy practice loss and in order to maintain the principles of competency-based medical education, was adopted in another setting. Interventions delivering a standardized form of learner-centered training including video conferencing, audience response systems, as well as simulation-based endoscopy teaching courses were employed, having a stronger focus on achieving competencies rather than procedural numbers (23). Hands-on models procedures and simulationbased training could be another useful alternative (29). Beyond acquaintance with an advanced endoscopy method (i.e. endoscopic submucosal dissection - ESD), hands-on can be used to establish endoscopic skills among novices endoscopists and strengthen already known techniques in more advanced ones $(2,30)$. The utility of ex vivo and live models may be questionable due to their limited availability and additional financial burden, but it is surprising how efficiently they can be replaced by plastic models that are cost-effective and easy to assemble, with everyday materials that could potentially even be used in a fellow`s home $(31,32)$. In the era of a pandemic these models may be particularly useful for novice endoscopists, since a marked disruption in the first-year of endoscopic training has been noticed, while decrement in endoscopy competency due to breaks concerning advanced fellows is minimum (21,33). Similarly, the beneficial effect of implementing virtual reality simulator technology particularly in the early phase of training, resulting in shorter learning curve and performance optimization in the endoscopy suite has already been addressed $(34,35)$. Although appealing, this option seems to be depending on the expertise of each endoscopist, while the significant cost bears an additional caveat. A third strategy involves implementation of measures towards the direction of making up for lost endoscopic training time and to serve the huge backlog of deferred cases (36). This could be achieved by adding ambulatory endoscopy sessions (e.g., evening and/or weekend sessions), extension of fellowship program time or even workload increase in the post-pandemic era, practices that can balance the large case volumes along with provision of high-quality training. "Catchup" endoscopy training and extended training duration was favored as a solution to balance training decrement in the post-pandemic era by gastroenterology trainees in Australia (45\% and 36\%, respectively), a perception that seems to be commonplace $(49.4 \%)$ among their European colleagues, as well $(37,38)$.

\section{Clinical Training}

During the COVID-19 pandemic the shortage of PPE and struggle to limit exposure of medical personnel, led "traditional" visits to diminish both in duration and team size, while in a similar manner outpatient clinics drastically decreased (39). In this regard, tele-health (via online video sessions) and telemedicine (via phone) consultations, feature as a sustainable solution for outpatients seeking initial evaluation or follow-up due to presence of chronic diseases (15), solution that is also favored by a large proportion $(74 \%)$ of physicians $(74 \%)$ in a recent survey, as well (15). Results from a large web-based survey among US gastroenterology and hepatology providers (attending physicians, fellows, nurse practitioners, and physician assistants), showed almost universal adoption of telehealth from healthcare workers, with $87.9 \%$ of physicians reporting $>75 \%$ utilization in their centers (40). Notably, this percentage was even higher in gastroenterology fellows' clinics $(90 \%)$, while it has increased considerably compared to that previously reported $(47 \%$ of centers implemented $>75 \%$ telehealth) (6), highlighting the method's growing popularity. Similar results were obtained from two other surveys from USA and Australia, respectively. The former (16), documented a major shift in telehealth with the median number of telehealth visits per week per fellow being 5 (range $1-25$ ); 76\% of programs reported having fellows use telehealth in contrast to the $98 \%$ not using telehealth in the pre-COVID19. Didactics were moved to virtual conferences in $94 \%$ of the programs with fellows utilizing various online resources. Regarding bench laboratory research, $27 \%$ of the programs reported no fellows involved, while $89 \%$ reported fellows working from home. As far as clinical research was concerned, $25 \%$ of the programs reported no changes with most $61 \%$ reported institutional restrictions. The latter documented fellow involvement in almost all telehealth consultations sessions (99\%), following the pandemic crisis (37). Aside the outpatient clinic, telemedicine could be also incorporated in the management of hospitalized patients in the form of virtual clinical and imaging case review to determine subsequent diagnostic and treatment plans.

\section{Educational Training}

Although fellows are generally not primary investigators in clinical trials, they represent valuable collaborators contributing to vital steps of the whole process. This enables them to develop skills and improve their clinical decision making, through an in-depth knowledge of the evidence-based medicine process. Cancellation of national and international congresses has also deprived them of the opportunity of social networking, limiting their scientific perspectives. However, fellow-driven 
research can still be pursued through alternative study types (e.g., web-based surveys, retrospective studies, systematic review and meta-analysis) that can be carried out through distant collaboratorships and without patient interaction. Finally, fellows may also engage in high quality multicenter studies, as evidence by the successes of the observational COVID-SURG, Protect-ASUC, SECURE-IBD studies which predominantly relies on trainee recruitment of patients to advance an understanding of the impact of COVID in gastroenterology (41-43).

\section{Conclusion and prospects for future research}

COVID-19 has negatively impacted on multiple domains of gastroenterology training, particularly in relation to endoscopy, while the long-term consequences remain unclear. Accurately identifying training gaps will assist local and international scientific societies to pursue new measures in order to address the educational needs of fellows during and after the COVID-19 pandemic. Taking into account fellows' perceptions and use of new technologies are perhaps the key changes that should be pursued made in response to the ongoing pandemic.

\section{Conflicts of interest}

None declared

\section{Authors' contributions}

P Gkolfakis conceived the idea, acquired the data, performed the search, drafted and finally approved the manuscript; K Ekmektzoglou and G Tziatzios acquired the data, drafted and finally approved the manuscript; K Siau, K Pawlak, K Triantafyllou, T Rokkas and M Arvanitakis revised and finally approved the manuscript. JYC conceived and planned the idea and wrote the manuscript.

\section{References}

1. MARASCO G, MAIDA M. GI Training in the COVID-19 Era: A Problem of Global Concern. Dig Dis Sci. 2020; 65(11): 3405-6.

2. SOETIKNO R, ASOKKUMAR R, MCGILL SK, KALTENBACH T. Simulation-Based Mastery Learning for Practicing GastroenterologistsRenewed Importance in the Era of COVID-19. Am J Gastroenterol. 2020; 115(9): 1380-3.

3. GRANLEK IM, HASSAN C, BEILENHOFFU, ANTONELLI G, EBIGBO A, PELIISE M, et al. ESGE and ESGENA Position Statement on gastrointestinal endoscopy and the COVID-19 pandemic. Endoscopy. 2020; 52(6): 483-90.

4. SULTAN S, LIM JK, ALTAYAR O, DAVITKOV P, FEUERSTEIN JD, SIDDIQUE SM, et al. AGA Rapid Recommendations for Gastrointestinal Procedures During the COVID-19 Pandemic. Gastroenterology. 2020; 159(2): 739-58 e4.

5. BISWAS S, ALRUBAIY L, CHINA L, LOCKETTM, ELLIS A, HAWKESN. Trends in UK endoscopy training in the BSG trainees' national survey and strategic planning for the future. Frontline Gastroenterology. 2018; 9(3): 2007.

6. FORBES N, SMITH ZL, SPITZER RL, KESWANI RN, WANI SB, ELMUNZER BJ, et al. Changes in Gastroenterology and Endoscopy Practices in Response to the Coronavirus Disease 2019 Pandemic: Results From a North American Survey. Gastroenterology. 2020; 159(2): 772-4 e13.

7. PALCHAUDHURI S, GABREJ, PRENNER S, SOLGA S. COVID-2019.2 Reboot: Returning a GI Fellowship to Pre-pandemic Practices. Dig Dis Sci. 2020; 65(9): 2461-5.
8. REPICI A, PACE F, GABBIADINI R, COLOMBO M, HASSAN C, DINELLI M, et al. Endoscopy Units and the Coronavirus Disease 2019 Outbreak: A Multicenter Experience From Italy. Gastroenterology. 2020; 159(1): 363-6 e3.

9. MAIDA M, SFERAZZA S, SAVARINO E, RICCIARDELLO L, RERIPI A, MORISCO F, et al. Impact of the COVID-19 pandemic on Gastroenterology Divisions in Italy: A national survey. Dig Liver Dis. 2020; 52(8): 808-15.

10. SINONQUEL P, AERTS M, BADAOUI A, BISSCHOPS R, BLERO D, DEMEDTS I, et al. BSGIE survey on COVID-19 and gastrointestinal endoscopy in Belgium : results and recommendations. Acta Gastroenterol Belg. 2020; 83(2): 344-54.

11. AMERICAN SOCIETY FOR GASTROINTESTINAL ENDOSCOPY: guidance for trainees during the COVID-19 pandemic. Gastrointest Endosc. 2020; 92(3): 748-53.

12. PAWLAK KM, KRAL J, KHAN R, AMIN S, BILAL M, LUI RN, et al. Impact of COVID-19 on endoscopy trainees: an international survey. Gastrointest Endosc. 2020; 92(4): 925-35.

13. SIAU K, IACUCCI M, DUNCKLEY P, PENMAN I. The Impact of COVID-19 on Gastrointestinal Endoscopy Training in the United Kingdom. Gastroenterology. 2020; https://doi.org/10.1053/j.gastro.2020.06.015. [Epub ahead of print].

14. MARASCO G, NARDONE OM, MAIDA M, BOSKOSKI I, PASTORELLI L, SCALDAFERRI F, et al. Impact of COVID-19 outbreak on clinical practice and training of young gastroenterologists: A European survey. Dig Liver Dis. 2020; 52(12): 1396-402.

15. CLARKE K, BILAL M, SANCHEZ-LUNA SA, DALESSIO S, MARANKI JL, SIDDIQUE SM. Impact of COVID-19 Pandemic on Training: Global Perceptions of Gastroenterology and Hepatology Fellows in the USA. Dig Dis Sci. 2020 Oct 19; 1-5.

16. MALLON D, POHL JF, PHATAK UP, FERNANDES M, ROSEN JM, LUSMAN SS, et al. Impact of COVID-19 on Pediatric Gastroenterology Fellow Training in North America. J Pediatr Gastroenterol Nutr. 2020; 71(1): 6-11.

17. ZORNIAK M, SIRTL S, MAHAJAN UM, STUBBE HC, CHAPULA M, WOSIEWICZ P, et al. Influence of COVID-19 pandemic on endoscopic procedures in two European large-capacity endoscopy units: "keep calm, keep safe and scope on"? Dig Dis. 2020. 2020 Aug 24. Online ahead of print.

18. ROEMMELE C, MANZENDER J, MESSMANN H, EBIGBO A. Impact of the COVID-19 outbreak on endoscopy training in a tertiary care centre in Germany. Frontline Gastroenterol. 2020; 11(6): 454-7.

19. BOSKOSKI I, COSTAMAGNA G. Gastrointestinal endoscopy and the COVID-19 pandemic: Urgent issues in endoscopic retrograde cholangiopancreatography and endoscopic training. United European Gastroenterol J. 2020; 8(6): 743-4.

20. BOSKOSKI I, PECERE S, BOVE V, BARBARO F, PERRI V, COSTAMAGNA G. Impact of SARS-CoV-2 on a high volume endoscopy center in Italy. Dig Liver Dis. 2020; 52(8): 819-22.

21. KUMAR S, PRENNER S, KOCHMAN ML. The Impact of COVID-19 on Endoscopic Training. Am J Gastroenterol. 2020; 115(7): 1142-3.

22. PALCHAUDHURI S, GABRE J, PRENNER S, KLAPPROTH JM. Adapting a GI Fellowship to a Pandemic: Novel Approaches to Accommodating a Novel Virus. Dig Dis Sci. 2020; 65(6): 1562-5.

23. ONG AM. Impact of COVID-19 on medical education and resident burnout in a postgraduate programme. Singapore Med J. 2020. 2020 Jun 26. Online ahead of print.

24. KESWANI RN, KEEFER L, SURAWICZ CM. Burnout in Gastroenterologists and How to Prevent it. Gastroenterology. 2014; 147(1): 11-4.

25. BUSCARINI E, GECSE KB, TINIAKOS D. Burnout among gastroenterologists: How to manage and prevent it. United European gastroenterology journal. 2020; 8(7): 832-4.

26. CRAVERO AL, KIM NJ, FELD LD, BERRY K, RABIEE A, BAZARBASHI $\mathrm{N}$, et al. Impact of exposure to patients with COVID-19 on residents and fellows: an international survey of 1420 trainees. Postgrad Med J. 2020. Oct 21; postgradmedj-2020-138789.

27. ONG AM. Outrunning Burnout in a GI Fellowship Program During the COVID-19 Pandemic. Dig Dis Sci. 2020; 65(8): 2161-3.

28. MEJIA PEREZLK, SHARMA N. Endoscopy training during COVID-19. Gastrointest Endosc. 2020; 92(4): 988.

29. SIDDIQUI UD, ASLANIAN HR. The New Virtual Reality: Advanced Endoscopy Education in the COVID-19 Era. Dig Dis Sci. 2020; 65(7): 1888-91.

30. WALSCH CM, SCAFFIDI MA, KHAN R, ARORA A, GIMPAYA N, LIN $\mathrm{P}$, et al. Non-technical skills curriculum incorporating simulation-based training improves performance in colonoscopy among novice endoscopists: Randomized controlled trial. Digestive Endoscopy. 2020; 32(6): 940-8.

31. GKOLFAKIS P, TZIATZIOS G, PAPADOPOULOS V, DIMITRIADIS GD, GEORGOPOULOS SD, TRIANTAFYLLOU K. A nationwide survey of training satisfaction and employment prospects among Greek gastroenterology fellows during the economic recession. Ann Gastroenterol. 2017; 30(2): 242-9. 
32. KOO CS, SIAH KTH, LOW HC, KOH CJ. A low-cost endoscopy trainer for novice endoscopy training in COVID-19. Endoscopy. 2020; 52(12): E463-E4.

33. JORGENSEN JE, ELTA GH, STALBURG CM, KOLARS JC, STOUT JM, KORSNES SJ, et al. Do breaks in gastroenterology fellow endoscopy training result in a decrement in competency in colonoscopy? Gastrointest Endosc. 2013; 78(3): 503-9.

34. COMMITEE AT, GOODMANAJ, MELSON J, ASLANIAN HR, BHUTANI MS, KRISHNAN K, et al. Endoscopic simulators. Gastrointest Endosc. 2019; 90(1): 1-12

35. WALSH CM, COHEN J, WOODS KL, WANG KK, ANDERSEN DK, ANDERSON MA, et al. ASGE EndoVators Summit: simulators and the future of endoscopic training. Gastrointest Endosc. 2019; 90(1): 13-26.

36. PEERY AF, CROCKETT SD, MURPHY CC, LUND JL, DELLON ES, WILLIAMS JL, et al. Burden and Cost of Gastrointestinal, Liver, and Pancreatic Diseases in the United States: Update 2018. Gastroenterology. 2019; 156(1): 254-72 e11.

37. PRINCE DS, LIU K, PAVENDRANATHAN G, STRASSER SI, BOLLIPO S KAZANAKI R. The impact of the COVID-19 pandemic on gastroenterology trainees in Australia. J Gastroenterol Hepatol. 2020; 35(10): 1841-2.

38. KARAMPEKOS G, GKOLFAKIS P, TZIATZIOS G, APOSTOLOPOULOS P, VLACHOGIANNAKOS J, THOMOPOULOS K, et al. Differences between fellows and fellowship program directors in their perception of the impact of the COVID-19 pandemic on gastroenterology training: results from a nationwide survey in Greece. Ann Gastroenterol. 2020; 33(6): 680-6.

39. KESWANI RN, SETHI A, REPICI A, MESSMANN H, CHIU PW. How To Maximize Trainee Education During the Coronavirus Disease-2019 Pandemic: Perspectives From Around the World. Gastroenterology. 2020; 159(1): 26-9.

40. KEIHANIAN T, SHARMA P, GOYAL J, SUSSMAN DA, GIROTRA M. Telehealth Utilization in Gastroenterology Clinics Amid the COVID-19 Pandemic: Impact on Clinical Practice and Gastroenterology Training. Gastroenterology. 2020; 159(4): 1598-601.

41. SEBASTIAN S, WALKER GJ, KENNEDY NA, CONLEY TE, PATEL $\mathrm{KV}$, SUBRAMANIAN S, et al. Assessment, endoscopy, and treatment in patients with acute severe ulcerative colitis during the COVID-19 pandemic (PROTECT-ASUC): a multicentre, observational, case-control study. Lancet Gastroenterol Hepatol. 2021. Apr; 6(4): 271-281.

42. WINDSOR JW, UNDERWOOD FE, BRENNER E, COLOMBEL JF, KAPPELMAN MD, UNGARO R, et al. Data Visualization in the Era of COVID-19: An Interactive Map of the SECURE-IBD Registry. Am J Gastroenterol. 2020; 115(11): 1923-4.

43. GLOBALSURG C, National Institute for Health Research Global Health Research Unit on Global S. Global variation in postoperative mortality and complications after cancer surgery: a multicentre, prospective cohort study in 82 countries. Lancet. 2021; 397(10272): 387-97. 